\title{
PRODUCTION OF Trichophyton mentagrophytes ANTIGENS AND THEIR CHARACTERIZATION IN MICE
}

\author{
VENTURINI J (1, 2), ROSSI-FERREIRA R (1), ARRUDA, MSP (1)
}

(1) Department of Biological Science, School of Science, São Paulo State University, UNESP, Bauru, São Paulo State, Brazil; (2) Graduate Program in Tropical Diseases, Botucatu Medical School, São Paulo State University, UNESP, Botucatu, São Paulo State, Brazil.

ABSTRACT: The participation of dermatophytic antigens in the host-parasite balance is still poorly understood. One of the difficulties encountered by researchers is the lack of dominant and specific antigens that can be used in such studies. In order to contribute to a better understanding of this aspect of infection, the present study identifies antigen fractions obtained from exoantigen and cytoplasmic extracts of Trichophyton mentagrophytes. Sodium dodecyl sulfate polyacrylamide gel electrophoresis (SDS-PAGE) revealed the presence of 13 proteins in the exoantigen extract, whose molecular weight ranged from 12.5 to $90 \mathrm{kDa}$. The cytoplasmic extract contained 18 protein fractions ranging from 11 to $110 \mathrm{kDa}$. Immunoblotting showed the presence of immunodominant antigens against $\lg G$, $\lg M$ and $\lg A$ antibodies. This affinity was observed in three proteins of the exoantigen extract and in three proteins of the cytoplasmic extract, with respective molecular weights of 33, 39 and 59, and 40,55 and $82 \mathrm{kDa}$. These results are promising, especially when considering that these extracts contain antigenically distinct protein fractions which, once determined, may contribute to a better understanding of dermatophytoses, and may thus help in the development of alternative strategies for the diagnosis and treatment of this condition.

KEY WORDS: Trichophyton mentagrophytes, antigens.

CONFLICTS OF INTEREST: There is no conflict.

FINANCIAL SOURCE: FUNDUNESP and FAPESP.

\section{CORRESPONDENCE TO:}

JAMES VENTURINI, Laboratório de Imunopatologia Experimental, Departamento de Ciências Biológicas, Faculdade de Ciências, Universidade Estadual Paulista, UNESP, Av. Eng. Luiz Edmundo Carrijo Coube, s/n, Bauru, SP, 17033-360, Brasil. Phone/Fax: +55 14 3103 6078. Email: james@fc.unesp.br. 
J. Venturini et al. PRODUCTION OF Trichophyton mentagrophytes ANTIGENS AND THEIR CHARACTERIZATION IN MICE. J. Venom. Anim. Toxins incl. Trop. Dis., 2008, 14, 3, p. 410

\section{INTRODUCTION}

Dermatophytes comprise a group of fungi that use keratin as food source and invade keratinized tissues of humans and animals, causing an infection called dermatophytosis, more commonly known as tinea (14). Dermatophytoses are among the most common zoonoses worldwide and in view of their increasing incidence in children, adolescents and adults over the past decades, have become an important public health problem (19).

Susceptibility to this infection, especially its chronic forms, has been associated with a series of disorders or therapeutic procedures that reduce the efficacy of certain immunological functions (5). According to the literature, a greater predisposition to these infections is observed in patients with diabetes mellitus (28), atopia (30) and AIDS (25), among others. Patients undergoing corticosteroid therapy are also considered to be more susceptible to dermatophytoses (13). Although these studies indicate that the cellular immune response plays an important role in the modulation of this infection, patients with dermatophytoses, even those severely ill, often exhibit skin reactivity to trichophytin, i.e., the disease progresses even in the presence of delayed-type hypersensitivity (9). The same applies to humoral immunity, with higher antibody titers being observed during chronic dermatophytic infections, indicating that these antibodies are not efficient in overcoming the infection $(6,32)$.

Although the literature attributes a small role to humoral immunity in the control of dermatophytic infections, Sparker et al. (27) suggested that fungus-specific antibodies may exert a direct fungicidal effect through opsonization and activation of the complement system and thus contribute to the resolution of infection. Nevertheless, studies involving the genus Trichophyton are rare and seem to depend on the fungal antigen employed. Honbo et al. (16) detected discretely elevated IgA and IgE levels in patients with chronic dermatophytoses in response to two $T$. mentagrophytes antigens, specifically one polysaccharide and one peptide antigen. Leibovici et al. (22), in turn, demonstrated a significant increase of nonspecific lgE and specific IgG4 levels in response to $T$. rubrum antigen in a patient with chronic dermatophytosis. Using hyperimmune rabbit serum, Garg and Muller (11) isolated 17 antigen proteins obtained from T. mentagrophytes extracts. Zrimsek and DrobnicKosorok (33), using rabbits naturally infected with $T$. mentagrophytes, observed $100 \%$ specificity for three antigens. 
In view of the scarcity of studies in this area and since these antigens may contribute to the development of alternative strategies for the immunodiagnosis of dermatophytic infections and also serve as a tool in the study of the immune response role in dermatophytoses, we characterized the antigen potential of substances obtained from exoantigen and cytoplasmic extracts of $T$. mentagrophytes.

\section{MATERIALS AND METHODS}

\section{Exocellular Antigen Production}

The T. mentagrophytes strain (2118/99-ILSL) was isolated from human lesion and obtained from the fungal collection of the Lauro de Souza Lima Institute, Bauru, São Paulo State, Brazil and was maintained by frequent subculture (every six months) on Mycosel囚 agar (Difco Laboratories, USA) slant at $25^{\circ} \mathrm{C}$ in our laboratory since 1999. The total fungal growth was transferred to a 2,800 $\mathrm{mL}$ Fernbach flask containing 500 $\mathrm{mL}$ of Sabouraud's liquid medium (2\% peptone; $2 \%$ glucose; $0.05 \%$ chloramphenicol) and stored at $25^{\circ} \mathrm{C}$ in a rotary incubator at $50 \mathrm{rpm}$ (ETICA Equipamentos, Brazil). After 10 days of incubation, the fungal culture supernatants were killed with merthiolate $(0.2 \mathrm{~g} / \mathrm{L})$ and collected following paper filtration, concentrated in a vacuum at 45 to $50^{\circ} \mathrm{C}$ and dialyzed against distilled water, for 24 hours, $4^{\circ} \mathrm{C}$, with four changes of the dialysis membrane $(10,000-12,000 \mathrm{~g} / \mathrm{mol}$ molecular weight exclusion limit) (3).

\section{Cytoplasmic Antigen Production}

The material retained on the filter was fractioned with liquid nitrogen, in order to break the fungal walls and membranes. Five milliliters of phosphate buffered saline (PBS) was added to the sample and homogenized in a vortex mixer. The homogenate was then centrifuged at $13,000 \times \mathrm{g}$ for 30 minutes at $4^{\circ} \mathrm{C}$. The supernatant (which contained the cytoplasmic antigen) was recovered and a protease inhibitor containing $1 \mathrm{mM}$ phenylmethylsulfonyl fluoride (Sigma, USA) was added (4). The protein concentration of exocellular and cytoplasmic antigens was determined by the Bradford method (2). 
J. Venturini et al. PRODUCTION OF Trichophyton mentagrophytes ANTIGENS AND THEIR CHARACTERIZATION IN MICE. J. Venom. Anim. Toxins incl. Trop. Dis., 2008, 14, 3, p. 412

\section{Sodium Dodecyl Sulfate Polyacrylamide Gel Electrophoresis (SDS-PAGE)}

Exocellular and cytoplasmic antigens obtained as described above were separated by SDS-PAGE (21) and were carried out on a $12 \%$ separating polyacrylamide gel and $4 \%$ stacking gel in a Mini Protean II® apparatus (Bio-Rad, USA). Respectively, 2 and $10 \mu \mathrm{g}$ of proteins were applied to each slot of SDS-PAGE and immunoblotting assays. Protein standards (MoBiTec, Germany) with the following molecular weights were used: $\beta$-galactosidase (E. coli) $116 \mathrm{kDa}$; phosphorylase b (rabbit muscle) 97.4 $\mathrm{kDa}$; bovine serum albumin (bovine plasma) $62.2 \mathrm{kDa}$; alcohol dehydrogenase (yeast) $37.6 \mathrm{kDa}$; carbonic anhydrase (bovine erythrocytes) $28.8 \mathrm{kDa}$; myoglobin (horse skeletal muscle) $18.4 \mathrm{kDa}$ and lysozyme (chicken egg white) 14 kDa. Proteins were visualized by silver staining (1).

\section{Immunization}

Thirty 2-month-old male Swiss mice from the Animal House of São Paulo State University, Brazil, were divided into three groups. The first group consisting of ten animals was immunized with exocellular antigens. Another group was immunized with cytoplasmic antigens, and the other ten animals were used as control group. The mice were immunized intraperitoneally on days 0, 21 and 42 with antigens (50 $\mu \mathrm{g}$ of protein $/ \mathrm{mL}$ ) and adjuvant aluminum hydroxide (Merck, Germany). Control animals received identical courses of sterile saline solution plus adjuvant. Three days after the last inoculation, the animals were sacrificed by carbon dioxide asphyxiation and blood was collected. The serum was separated and stored at $-20^{\circ} \mathrm{C}$ (26). The study was approved by the Ethics Committee of the College of Sciences, São Paulo State University, Bauru, São Paulo State, Brazil.

\section{Enzyme-linked Immunosorbent Assay (ELISA)}

$\lg G$, IgM and $\lg A$ antibodies against the exocellular and cytoplasmic antigens were measured by ELISA according to the description of Mamoni et al. (23), modified as follows: the microtiter plates (Maxisorp, Denmark) were coated with $5 \mu \mathrm{g} / \mathrm{well}$ of antigen. A 1:50 dilution of sera in PBS with 1\% bovine serum albumin (Merck) was prepared, with dilutions halving the ratio until 1:6,400. Negative control sera in parallel were added on each plate. Antimouse $\lg G$, $\lg \mathrm{M}$ and $\lg \mathrm{A}$ conjugated to horseradish peroxidase (HRP) (Santa Cruz Biotechnology, USA) were used at a 
dilution of $1: 5,000$ in PBS. The endpoint was defined by mean +2 standard deviations of the absorbance obtained with the sera of healthy mice.

\section{Immunoblotting}

After electrophoresis, the proteins were transferred to nitrocellulose paper (NCP) (Bio-Rad) at 120 volts in a transblotting chamber (Bio-Rad) for 2.5 hours (29). The free sites on the nitrocellulose paper were blocked with $5 \%$ nonfat dry milk (Nestle, Brazil) in $0.01 \mathrm{M}$ Tris buffer for 2 hours. The NCP was sliced vertically, and the strips were incubated individually for 60 minutes at room temperature with sera from hypermunizated mice diluted at 1:20 in PBS containing $0.02 \%$ Tween 20 and $0.25 \%$ gelatin. The membranes were then incubated with antimouse $\lg G, \lg M$ and $\lg A$ conjugated to HRP (Santa Cruz Biotechnology) in a dilution of 1:10,000 in PBS, for 1 hour at $37^{\circ} \mathrm{C}$. The reaction was developed in a solution containing $5 \mathrm{mg}$ of 3,3'diaminobenzidine (Sigma) and $190 \mu \mathrm{L}$ of hydrogen peroxide $\left(\mathrm{H}_{2} \mathrm{O}_{2}\right)$ in $50 \mathrm{~mL}$ of Tris buffer, $\mathrm{pH}$ 7.4. The membranes were washed and dried, stored and analyzed. Molecular weight was determined using LabWorks $3.02 \AA$ analysis software (UVP Laboratory Product, USA).

\section{RESULTS}

Total protein contents in the exoantigen and cytoplasmic extracts determined by the method of Bradford were 2,100 and $1,800 \mu \mathrm{g} / \mathrm{mL}$, respectively. SDS-PAGE of the exoantigen extract followed by silver staining permitted the separation of 13 clearly visible protein bands (Figure 1, column A). The fractions detected had molecular weights ranging from 12 to approximately $90 \mathrm{kDa}(12,16,20,28,29,32.5,34.5,36$, 44.5, 53, 59, 67 and $89 \mathrm{kDa}$ ). One more evident complex of fractions was detected between 33 and $67 \mathrm{kDa}$, with emphasis on the fractions of approximately 16 and 59 $\mathrm{kDa}$ (indicated by arrows). SDS-PAGE of the cytoplasmic extract showed 18 proteins (Figure 1, column B), whose molecular weights ranged from 11 to $110 \mathrm{kDa}(11,14$, $15,16,21,24,26,27,28,32,33,36,40,55,61,65,82$ and 110 kDa), with emphasis on the fractions of 55 and $82 \mathrm{kDa}$.

Next, the antigen components of the exoantigen and cytoplasmic extracts of $T$. mentagrophytes were characterized in Swiss mice. First, we evaluated the efficacy of hyperimmunization of animals by investigating specific serum antibodies against 
the antigens produced using an enzyme immunoassay (ELISA). The results summarized in Figure 2 show optical density values above the endpoint, a finding confirming successful antibody production. Afterwards, immunoblotting was used to determine the molecular weight of the antigen fractions. Using the exoantigen, the sera reacted with three protein fractions against three different types of immunoglobulins (IgG, IgM and $\lg A$ ), whose molecular weights were approximately 33, 39 and $59 \mathrm{kDa}$ (Figure 3A). Using the cytoplasmic antigen, the sera exhibited the same reactivity pattern but with different fractions of approximately 40, 55 and 82 kDa (Figure 3B).

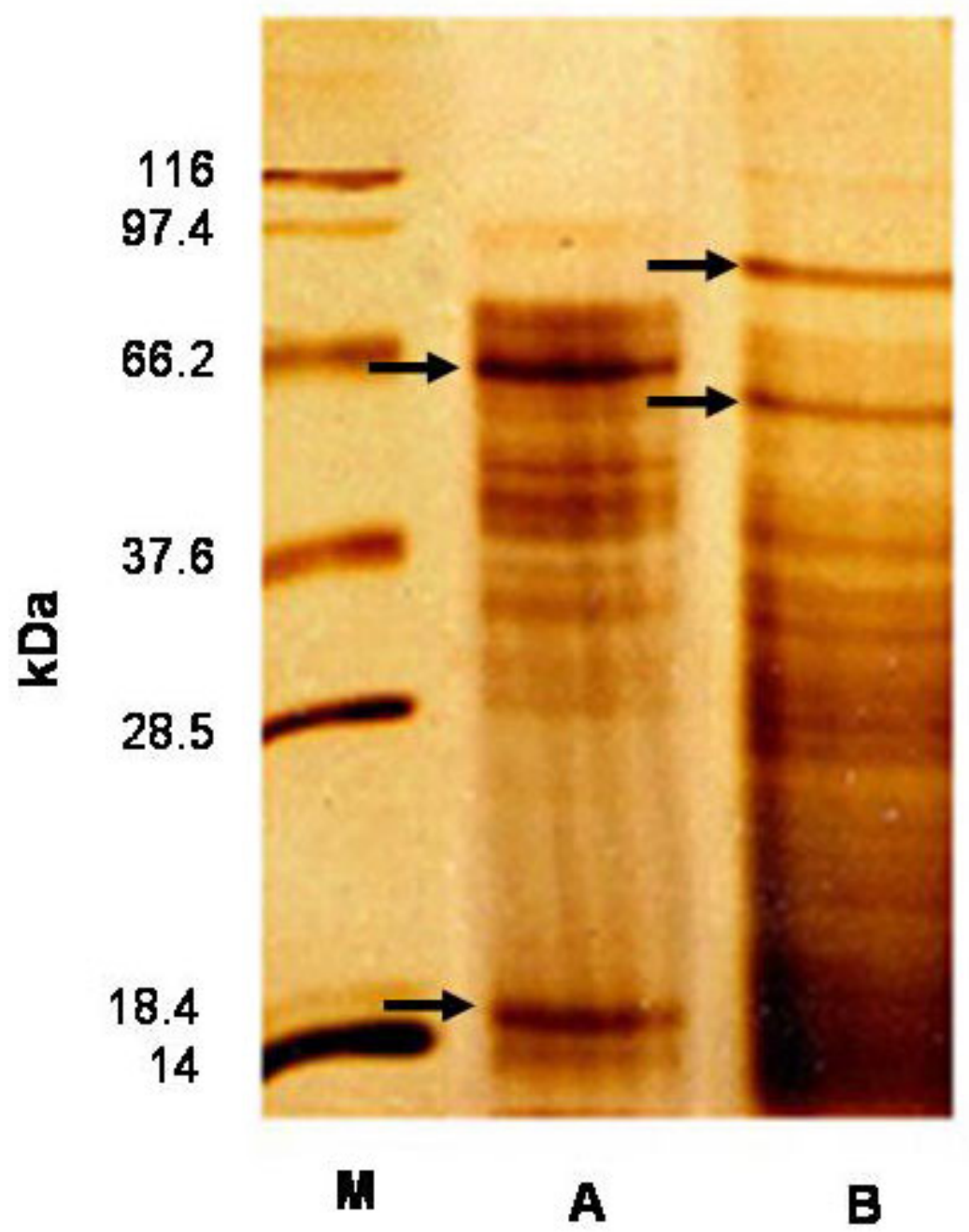

Figure 1. Sodium dodecyl sulfate polyacrylamide gel electrophoresis (SDS-PAGE) of the antigen preparations.

Column M: molecular weight standards; column A: exoantigen extract; column B: cytoplasmic extract. 
J. Venturini et al. PRODUCTION OF Trichophyton mentagrophytes ANTIGENS AND THEIR CHARACTERIZATION IN MICE. J. Venom. Anim. Toxins incl. Trop. Dis., 2008, 14, 3, p. 415
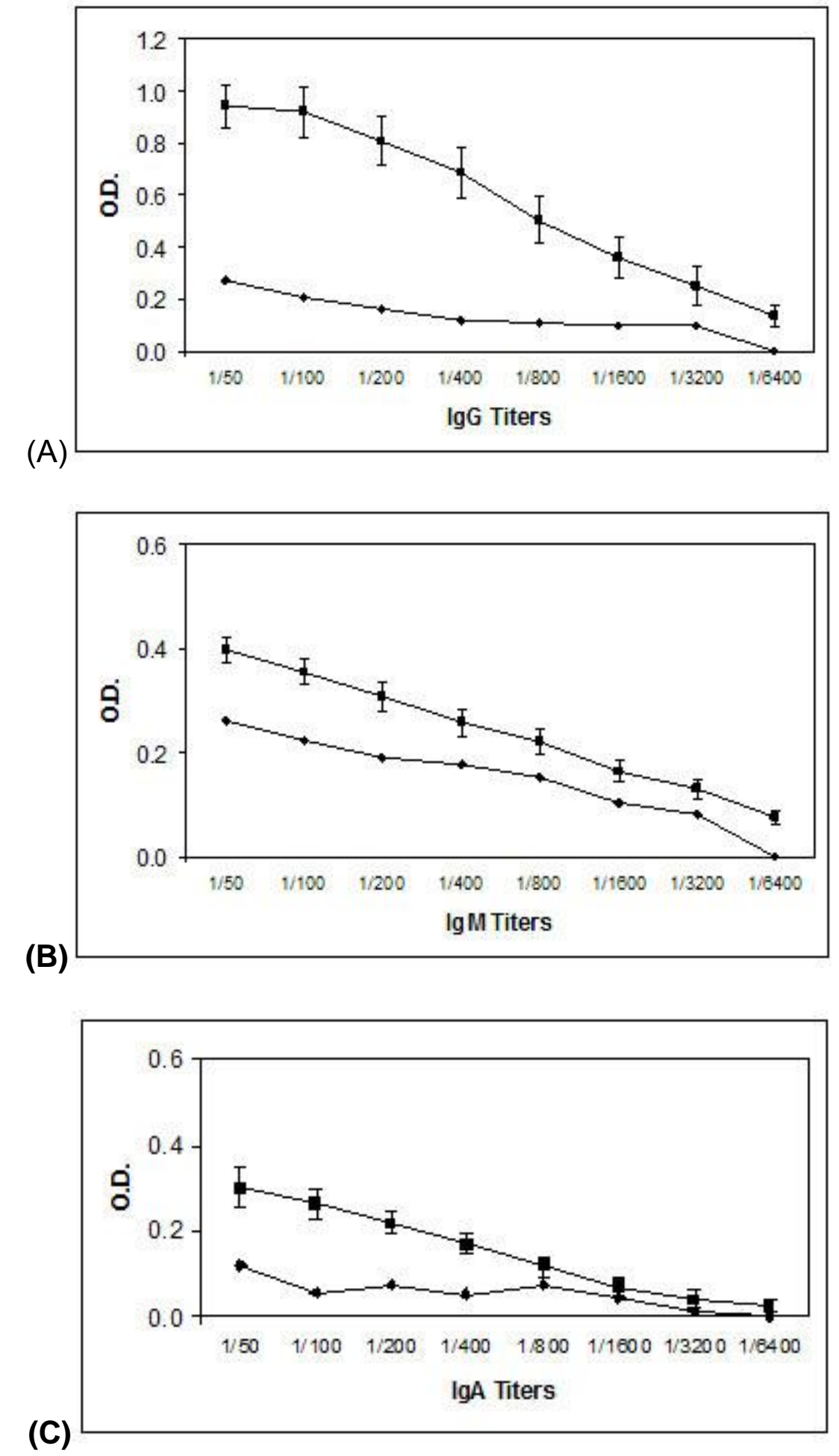

Figure 2. Detection of $\lg G(A), \lg M(B)$ and $\lg A(C)$ antibodies against $T$. mentagrophytes antigens in hyperimmunized Swiss mice.

- = immunized animals (data are reported as means \pm SE); $\boldsymbol{\Delta}=$ endpoint. 


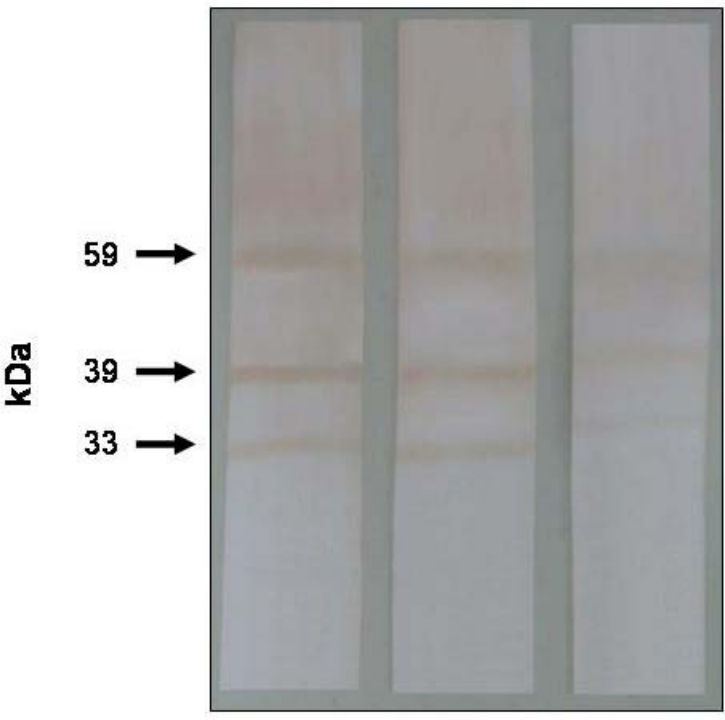

(A)

$\lg G \quad \lg M \quad \lg A$

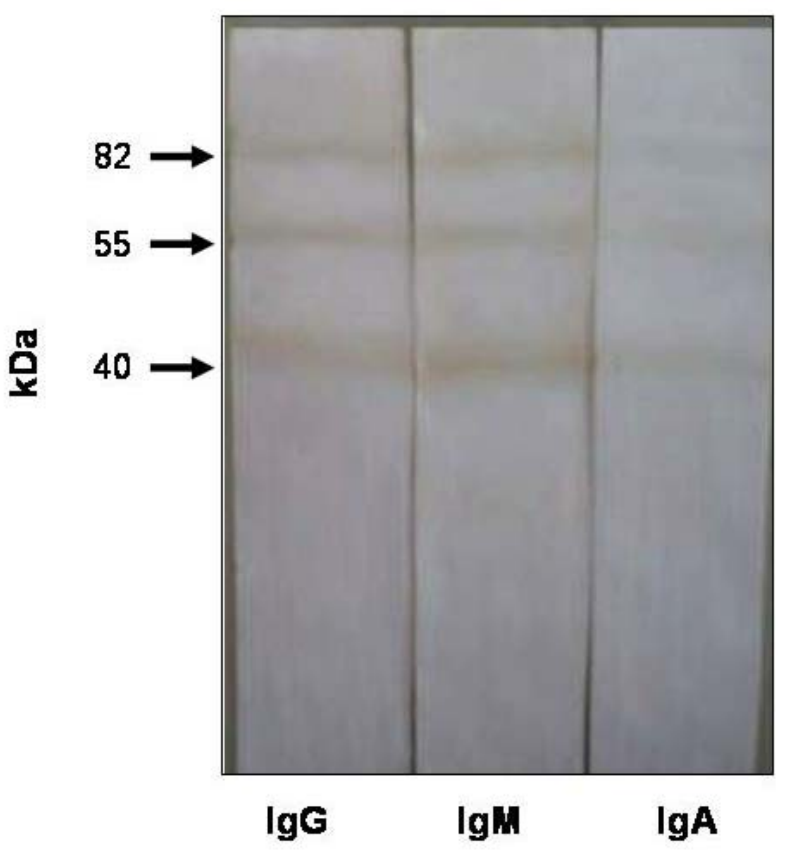

Figure 3. Immunoblot of both exoantigen (A) and cytoplasmic (B) extracts of $T$. mentagrophytes. Immunodominant IgG, IgM and IgA fractions are indicated by arrows and are expressed as $\mathrm{kDa}$. 


\section{DISCUSSION}

One of the obstacles encountered by researchers studying the immune response in dermatophytoses is the lack of specific, reproducible and available antigens (8). In most cases, poorly distinct antigen preparations obtained from different materials have been used. In 1983, Huppert (17) identified different variables that may affect the comparison of the results reported by various researchers. One variable is the origin of the antigen extract, since the fungi can grow on solid as well as in liquid medium. In addition, liquid cultures can be incubated in a stationary manner or under shaking, and other substances such as antibiotics may or may not be added to the culture medium. Another variable is the source employed, i.e., fungal cells (live or dead) or culture filtrates, or even whether the preparations are used in natura or are submitted to procedures of concentration, ultrafiltration and/or precipitation with chemical agents. Thus, the exact description of the method applied is essential to obtain equivalent antigens.

These observations are pertinent when fungal extracts are employed. Similar to other investigations, in the current study the presence of exoantigen $(7,10,24,31)$ and cytoplasmic $(20,27,31,32)$ antigens was detected. Under the conditions tested, the culture filtrate (exoantigen) exhibited 13 protein fractions and the extract retained on the filter (cytoplasmic antigen) presented 18 fractions. Differences in both number and staining intensity of the protein fractions between these extracts have also been reported by Zaitz (31), who detected 15 fractions in the culture filtrate and 30 fractions retained on the filter, whose molecular weights ranged from 12.5 to 100 kDa.

Nevertheless, the divergences between our results and those reported by other investigators studying T. mentagrophytes under similar experimental conditions may be attributed to numerous factors such as the lack of a standard culture of $T$. mentagrophytes for the preparation of the antigen suspensions, the culture medium used, and/or the growth phase of the fungus at the time of extract preparation, i.e., mycelial or arthroconidial phase $(11,20)$. Whereas Zrimsek and Drobnic-Kosorok (32), for example, utilized 21-day-old culture of T. mentagrophytes, after preliminary study we were able to establish a favorable growth condition for antigen production in 10-day-old culture by using T. mentagrophytes in the mycelial phase and simple Sabouraud broth. 
In order to evaluate the immunogenic proteins of the antigens, immunoblotting and hyperimmune sera obtained from Swiss mice were employed. The exoantigen and cytoplasmic extracts of $T$. mentagrophytes were found to contain immunodominant proteins able to provoke the production of $\operatorname{Ig} \mathrm{M}$, $\operatorname{Ig} \mathrm{A}$ and, especially, $\lg G$ antibodies. The marked presence of IgG was expected since we used a longer immunization scheme for our animals (26).

The development of humoral immunity in dermatophytic infections has been demonstrated in various studies. Different serological techniques such as immunodiffusion, complement fixation, immunoelectrophoresis, ELISA and Western blotting have been used to demonstrate the ability of dermatophytes to induce this type of response $(12,18,27,33)$. Specifically, in the case of chronic trichophytic infections, both a discrete increase in serum IgG and IgA titers (16) and the lack of a significant difference between these patients and infection-free individuals (15) have been documented. Similarly, Sparker et al. (27), using M. canis antigens, observed no significant differences in the production of IgG or IgM antibodies between cats infected with $M$. canis and those infected with other dermatophytes. On the other hand, Zrimsek and Drobnic-Kosorok (33), employing antigens obtained from $T$. mentagrophytes in an ELISA test, confirmed a significant increase of specific IgG antibodies in serum of cats naturally infected with $M$. canis and in rabbits infected with $T$. mentagrophytes. According to these authors, the low sensitivity of the methods employed and the lack of immunodominant antigens may be responsible for the divergence in the results reported by different investigators. Our results support this suggestion, despite our use of hyperimmunized animals and the lack of studies using antibodies in hosts naturally infected with the fungus and heterologous serum sample, the present optical density values above the endpoint indicate that these antigens are promising for use in the immunodiagnosis of dermatophytoses. Similarly, the use of these antigens in delayed-type hypersensitivity skin tests is pertinent. For example, we have conducted experimental studies in our laboratory on mice infected with $T$. mentagrophytes, in which the animals were found to be nonreactive to the fungus when commercial trichophytin was used. However, the same animals reacted to Trichophyton when the extracts produced in the present study were used as antigen (unpublished data).

Thus, despite previous attempts to obtain antigens that are sufficiently efficacious for use in studies on dermatophytoses, no well-established antigens are available. The 
present study contributed to the identification of such antigens, especially when considering that the extracts studied contained antigenically distinct protein fractions that, once isolated, may contribute to a better understanding of dermatophytoses and consequently, help in the development of alternative strategies for the diagnosis and treatment of this condition.

\section{ACKNOWLEDGEMENTS}

We are indebted to FUNDUNESP and FAPESP for financial support, and to Dr. Zoilo Pires de Carmargo and MSc Rodrigo Berzaghi (UNIFESP) for suggestions.

\section{REFERENCES}

1 ANSORGE W. Fast visualization of protein bands by impregnation in potassium permanganate and silver nitrate. In: STATHAKOS D. Eletrophoresis 82. Berlim: Walter de Gruyter, 1983, 235-42.

2 BRADFORD MM. A rapid and sensitive method for the quantification of microgram quantities of protein utilizing the principle of protein-dye biding. Anal. Biochem., 1976, 72, 248-54.

3 CAMARGO ZP., UNTERKIRCHER C., CAMPOY SP., TRAVASSOS LR. Production of Paracoccidioides brasiliensis exoantigens for immunodiffusion tests. J. Clin. Microbiol., 1988, 26, 2147-51.

4 CASOTTO M., PARIS S., CAMARGO ZP. Antigens of diagnostic value in three isolates of Paracoccidioides brasiliensis. J. Med. Vet. Mycol. 1991, 29, 243-53.

5 CESTARI TF., ABDALLA C., ASSIS TL. Fisiopatologia das dermatofitoses. An. Bras. Dermatol., 1990, 65, 310-6.

6 DAHL MV. Dermatophytosis and the imune response. J. Am. Acad. Dermatol., 1994, 31, S34-S41.

7 DE HAAN P., WIKLER JR., VAN DER RAAY-HELMER EM., BOORSMA DM. Antigens of dermatophytes and their characterization using monoclonal antibodies. Immunol. Ser., 1989, 47, 113-32.

8 DEUELL B., ARRUDA LK., HAYDEN ML., CHAPMAN MD., PLATTS-MILLS TA. Trichophyton tonsurans allergen. I. Characterization of a protein that causes immediate but not delayed hypersensitivity. J. Immunol., 1991, 147, 96-101. 
9 ELEWSKI BE., CHARIF ME., COOPER KD., GHANNOUM M., BIRNBAUM JE. Reactivity to trichophytin antigen in patients with onychomycosis: effect of terbinafine. J. Am. Acad. Dermatol., 2002, 46, 371-5.

10 FROTA MZM. Estudo "in vitro" da resposta imunológica de pacientes com dermatofitoses crônicas. Utilização de antígeno metabólico de Trichophyton rubrum. São Paulo: Universidade de São Paulo, Instituto de Ciências Biomédicas, 1998. 81p. [Master's thesis].

11 GARG AP., MULLER J. Preparations of antigens from Trichophyton mentagrophytes using a new semi-solid culture medium and their characterization by SDS-PAGE and immunological techniques. Mycoses, 1992, 35, 349-55.

12 GRAPPEL SF., BISHOP CT., BLANK F. Immunology of dermatophytes and dermatophytosis. Bacteriol. Rev., 1974, 38, 222-50.

13 GREENBERG HL., SHWAYDER TA., BIESZK N., FIVENSON DP. Clotrimazole/betamethasone diproprionate: a review of costs and complications in the treatment of common cutaneous fungal infections. Pediatr. Dermatol., 2002, 19, 78-81.

14 HAINER BL. Dermatophyte infections. Am. Fam. Physician., 2003, 67, 101-8.

15 HAMOUDA T., JEFFRIES CD., EKLADIOS EM., EL-MISHAD AM., EL-KOOMY M., SALEH N. Class-specific antibody in human dermatophytosis reactive with Trichophyton rubrum derived antigen. Mycopathol., 1994, 127, 83-8.

16 HONBO S., JONES HE., ARTIS WM. Chronic dermatophyte infections: Evaluation of the Ig class-specific antibody response reactive with polysaccharide and peptide antigens derived from Trichophyton mentagrophytes. J. Invest. Dermatol., 1984, 82, 287-90.

17 HUPPERT M. Antigens used for measuring immunological reactivity. In: HOWARD D. Fungi pathogenic for humans and animals, part B: pathogenicity and detection. New York: Marcel Dekker, 1983, 219-302.

18 KAAMAN T., VON STEDINGK LV., VON STEDINGK M., WASSERMAN J. ELISAdetermined serological reactivity against purified trichophytin dermatophytosis. Acta Dermat.- Venereol., 1981, 61, 313-7.

19 KANNAN P., JANAKI C., SELVI GS. Prevalence of dermatophytes and other fungal agents isolated from clinical samples. Indian J. Med. Microbiol., 2006, 24, 2125 . 
20 KOPECEK P., WEIGL E., RASKA M. Detection of antigens in mycelial and in arthroconidial phases of Trichophyton mentagrophytes. Folia Microbiol., 1998, 43, 702-6.

21 LAEMMLI UK. Cleavage of structural proteins during the assembly of the head of bacteriophage T4. Nature, 1970, 15, 680-5.

22 LEIBOVICI V., EVRON R., AXELROD O., WESTERMAN M., SHALIT M., BARAK V., FRANKENBURG S. Imbalace of immune responses in patients with chronic and widespread fungal skin infection. Clin. Exp. Dermatol., 1995, 20, 390-4.

23 MAMONI RL., NOUÉR SA., OLIVEIRA SJ., MUSATTI CC., ROSSI CL., CAMARGO ZP., BLOTTA MH. Enhanced production of specific $\lg G 4, \lg E$, IgA and TGF-beta in sera from patients with the juvenile form of paracoccidioidomycosis. Med. Mycol., 2002, 40, 153-9.

24 MUHSIN TM., AUBAID AH. Partial purification and some biochemical charactecristics of exocellular keratinase from Trichophyton mentagrophytes var. erinacei. Mycopathol., 2000, 150, 121-5.

25 PETMY LJ., LANDO AJ., KAPTUE L., TCHINDA V., FOLEFACK M. Superficial mycoses and HIV infection in Yaounde. J. Eur. Acad. Dermatol. Venereol., 2004, 8, 301-4.

26 ROSSI-FERREIRA R. Obtenção de anticorpo monoclonal murino anti-fator VIII da coagulação sangüínea. Botucatu: Universidade Estadual Paulista, Faculdade de Medicina, 2001. 161p. [Doctoral's thesis].

27 SPARKER AH., STOKES CR., GRUFFYDD-JONES TJ. SDS-PAGE separation of dermatophyte antigens, and western immunoblotting in feline dermatophytosis. Mycopathol., 1994, 128, 91-8.

28 TAN JS., JOSEPH WS. Common fungal infections of the feet in patients with diabetes mellitus. Drugs Aging, 2004, 21, 101-12.

29 TOWBIN H., STAEHELIN T., GORDON J. Electrophoretic transfer of proteins from polyacrylamide gels to nitrocellulose sheets: procedure and some applications. Proc. Natl. Acad. Sci. USA, 1979, 76, 4350-4.

30 WOODFOLK JA. Allergy and dermatophytes. Clin. Microbiol. Rev., 2005, 18, 3043. 
J. Venturini et al. PRODUCTION OF Trichophyton mentagrophytes ANTIGENS AND THEIR CHARACTERIZATION IN MICE. J. Venom. Anim. Toxins incl. Trop. Dis., 2008, 14, 3, p. 422

31 ZAITZ C. Produção de antígenos de Trichophyton mentagrophytes para estudo de aspectos imunológicos das dermatofitoses e das dermatofitides. São Paulo: Universidade Federal de São Paulo, Escola Paulista de Medicina, 1992. 122p. [Doctoral's thesis].

32 ZRIMSEK P., DROBNIC-KOSOROK M. Diagnostic potential of immunoblot analysis for identifying rabbits infected with Trichophyton mentagrophytes. Food Technol. Biotechnol., 2003, 41, 367-70.

33 ZRIMSEK P., DROBNIC-KOSOROK M. Diagnostic value of ELISA test for the detection of specific antibodies in cats and rabbits with dermatophytosis. Food Technol. Biotechnol., 2002, 40, 171-5. 